Groundwater / Early View

Case Study/

\title{
Stream Temperature Modeling and Fiber Optic Temperature Sensing to Characterize Groundwater Discharge
}

by Maryam Moridnejad $\boldsymbol{Z}$, Stewart Cameron, Asaad Y. Shamseldin, Floris Verhagen, Catherine Moore, Bruce W. Melville, Nick Dudley Ward

First published:03 September 2019

https://doi.org/10.1111/gwat.12938

Citations: 1

Article impact statement: Fiber optic temperature sensing and stream temperature modeling were used to characterize groundwater discharge in a stream in New Zealand.

\section{Abstract}

The Ngongotaha Stream was used as a case study to assess the applicability of fiber optic distributed temperature sensing (FODTS) to identify the location of springs and quantify their discharge. Thirteen springs were identified, mostly located within a $115 \mathrm{~m}$ reach, five discharged from the right bank and eight from the left bank. To quantify groundwater discharge, a new approach was developed in which the one-dimensional transient heat transport model was fitted to the FODTS measurements, where the main calibration parameters of interest were the unknown spring discharges. The spatial disposition of the groundwater discharge estimation problem was constrained by two sources of information; first, the stream gains $~ 500 \mathrm{~L} / \mathrm{s}$ as determined by streamflow gauging. Second, the temperature profiles of the left and right banks provide the spatial disposition of springs and their relative discharges. FODTS was used to measure stream temperature near the left and right banks, which created two temperature datasets. A weighted average of the two datasets was then calculated, where the weights reflected the degree of mixing between the right and left banks downstream of a spring. The new approach in this study marks a departure from previous studies, in which the general approach was to use the steady-state thermal mixing model (Selker et al. 2006a; Westhoff et al. 2007; Briggs et al. 2012) to infer groundwater discharge, which is then 
used as an input into a transient model of the general form of equation to simulate stream temperature (Westhoff et al. 2007).

\section{Citing Literature}

\section{NGWA

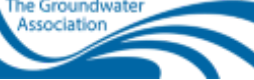

(⿻)

NATIONAL GROUNDWATER ASSOCIATION.ORG

ABOUT NGWA

ADVERTISING OPPORTUNITIES

CONTACT US

(c) 2020 National Groundwater Association

\section{About Wiley Online Library}

\section{Privacy Policy}

Terms of Use

Cookies

Accessibility

\section{Help \& Support}

Contact Us

\section{Opportunities}




\section{Connect with Wiley \\ The Wiley Network \\ Wiley Press Room}

